\title{
Hypertrophy of the Mandibular Coronoid Process and Structural Alterations of the Condyles Associated with Limited Buccal Opening: Case Report
}

\author{
Marcelo Oliveira MAZZETTO \\ Takami Hirono HOTTA \\ Discipline of Occlusion, Department of Restorative Dentistry, School of Dentistry of Ribeirão Preto, \\ University of São Paulo, Ribeirão Preto, SP, Brazil
}

\begin{abstract}
This paper reports the case of a patient who presented limited buccal opening, though, without apparent symptomatology. The patient was partially toothless and exodontia of the remaining teeth was indicated. Clinical examination and clinical interview were performed as well as panoramic radiograph, transcranial radiograph of the temporomandibular joints (TMJ) and, later, computed tomography (CT), emphasizing the importance of complementary exams in the diagnostic phase. Analysis of the CT scan confirmed the structural alteration in the condylar and coronoid processes of the jaw, explaining the limited buccal opening. The remaining teeth were extracted and complete upper and lower dentures were fabricated, reestablishing the occlusal relationship and the patient's stomatognathic functions. Surgical treatment of the coronoid process was discarded.
\end{abstract}

Key Words: hypertrophy of coronoid mandibular process, limitation of mouth opening, computed tomography.

\section{INTRODUCTION}

Limited mandibular movement appears to be an easy symptom to detect during clinical examination. However, relating this event to a specific cause can be a somewhat more complex task.

The measurements of normal maximum opening, incisal to incisal of the maxillary and mandibular teeth, are considered to vary between 40 and $60 \mathrm{~mm}(1)$, and the measurements of laterality and protrusion should be around $9 \mathrm{~mm}$ (2). When measurements are well beyond mean values, this can be related to muscular and intra-articular problems as well as ankylosis, neoplasia, inflammations, structural alterations and other factors. In addition, they also vary between researchers $(3,4)$.

In view of the diversity of etiological factors, there is a need to perform clinical examination and meticulous clinical interview, in addition to complementary exams. The enlargement of coronoid process is a structural alteration in which the increased coronoid process strikes against the zygomatic arch during the mandibular movements $(5,6)$. This is one of the circumstances in which the presence of clinical characteristics can be verified, such as limited opening. Displacement of the jaw to the side affected is usually an asymptomatic condition $(7,8)$.

The etiology is not fully explained (9); it could be related to osteochondroma, exostosis, osteoma, hypertrophy, hyperplasia and developmental alterations (7). The treatment proposed for this condition is resection of the coronoid process, (coronoidectomy) $(5,10,11)$ and biopsy to determine the histopathological nature of the isolated material.

This paper reports a case of hypertrophy of the coronoid process, structural alterations in the mandibular condyle and limited buccal opening. The patient underwent physical therapy and oral rehabilitation with complete dentures.

Correspondence: Prof. Dr. Marcelo O. Mazzetto, Faculdade de Odontologia de Ribeirão Preto, Departamento de Odontologia Restauradora, USP, Avenida do Café s/n, 14040-904 Ribeirão Preto, SP, Brasil. Tel: +55-16-3602-4020. Fax: +55-16-3633-0999. e-mail: mazzetto@forp.usp.br 


\section{CASE REPORT}

A 55-year-old man presented for dental treatment, complaining of difficulty in opening his mouth. Clinical examination of the mandibular arch showed micrognathia and absent teeth. In the maxillary arch, on the right side, tooth absence, residual roots (first molar) and some remaining teeth (first premolar, second premolar, and second molar) and, on the left side, the second molar, all with indication for extraction (Fig. 1).

In spite of the unfavorable oral condition, he did not present significant symptoms in the masticatory muscles that could explain the reduced opening $(32 \mathrm{~mm}$, from edge to edge). There was no alteration in the dimension, even with forcible digital manipulation.

As a result, complementary exams were requested such as panoramic radiograph, a transcranial radiograph of the temporomandibular joint (TMJ) and computed tomography.

In the panoramic and transcranial radiograph of TMJ, the presence of structural alterations was verified in the condyles, with an image compatible with osteoarthritis. By analysis of the computed tomography, the relationship of the coronoid process can be analyzed with the zygomatic process, in both the closed and open mouth positions. By the computed tomographic images, it was found that with mouth closed, the distances between the coronoid processes and the zygomatic processes of the right $(10.56 \mathrm{~mm})$ and left $(9.49 \mathrm{~mm})$ sides of the patient were practically the same. Comparing the images of the right (Fig. 2) and left (Fig. 3) sides of the patient with open mouth, it was verified that on

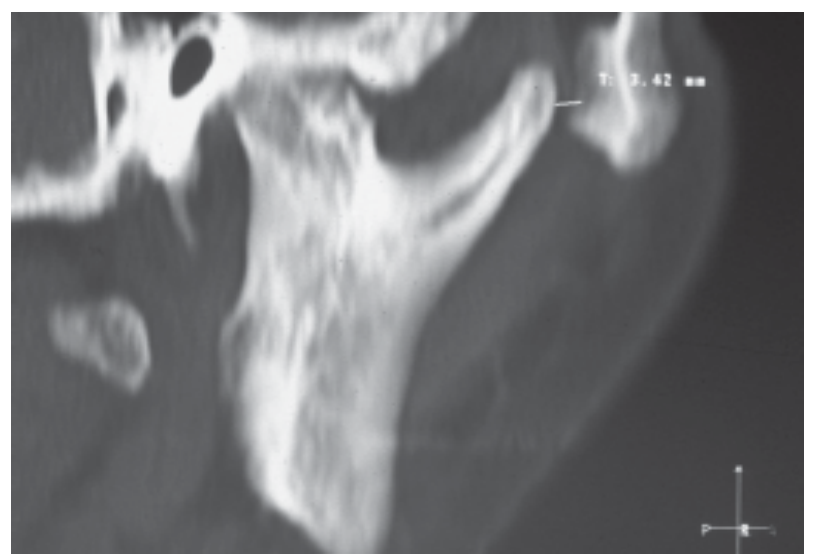

Figure 2: Computed tomography of TMJ right, open mouth. the left side the coronoid process maintained a distance of $7.73 \mathrm{~mm}$ from the zygomatic process, while, on the right side, the coronoid process was in close contact, at a distance of $3.42 \mathrm{~mm}$. This same relationship was confirmed by spiral computed tomography.

The patient was given explanations and counseling regarding his problem and treatment suggestions. Initially, to improve the condition of the masticatory muscles, physical therapy was initiated (stretching and against-resistance exercises, within painless limits). Maintenance of the patient's remaining teeth was unfeasible due to reduced bone support, the exodontia of these teeth and subsequent oral rehabilitation with complete dentures was suggested. The patient denied surgical intervention for correction of the hypertrophy of the coronoid process because that he was cardiopathic

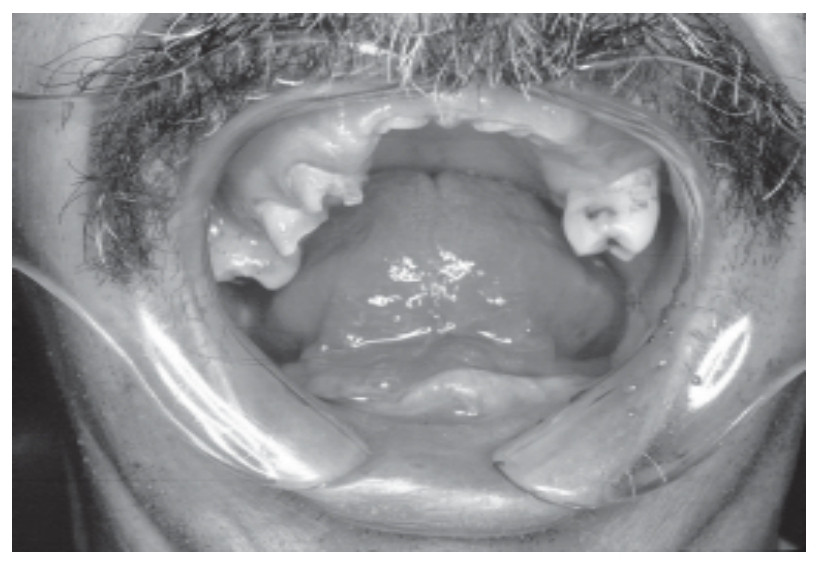

Figure 1. Mandibular and maxilar arches: teeth absence, residual roots, remaining teeth.

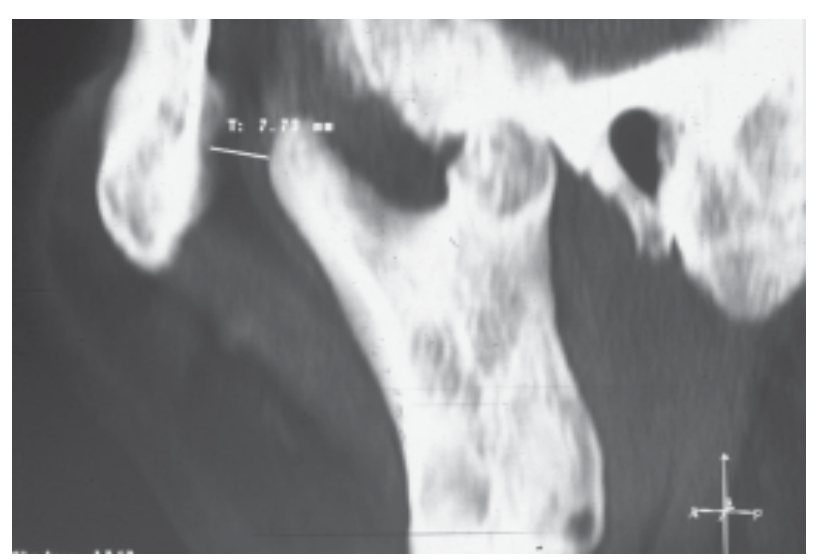

Figure 3. Computed tomography of TMJ left, open mouth. 
with arterial hypertension, rheumatoid arthritis, respiratory problems and was a drug addict.

After the therapies were applied, the patient showed an improvement in the signs and symptoms (Fig. 4) and expressed satisfaction with the treatment, which had improved both the esthetics and a mastication.

\section{DISCUSSION}

Under normal conditions, the jaw can be moved in all directions with a mean $10 \mathrm{~mm}$ for laterality, $9 \mathrm{~mm}$ for protrusion and 40-60 mm for opening. It may be assumed that there is some problem when the measurements of the movements are below these normal mean values.

The values of buccal opening that are considered to be limited, vary among researchers: from less than 40 $\mathrm{mm}$ (4) to around $37 \mathrm{~mm}$ (3).

In the present case, the patient presented buccal opening of around $32 \mathrm{~mm}$ (measured edge to edge). As this measurement remained unaffected, even with controlled downward manipulation of the mandibular arch, some structural incompatibility in the bone surface components of the TMS was suspected.Therefore the indicated complementary exams were performed, starting with the least complex (panoramic radiograph) followed by the most precise (computed tomography), according to the needs of the moment, for visualization of the

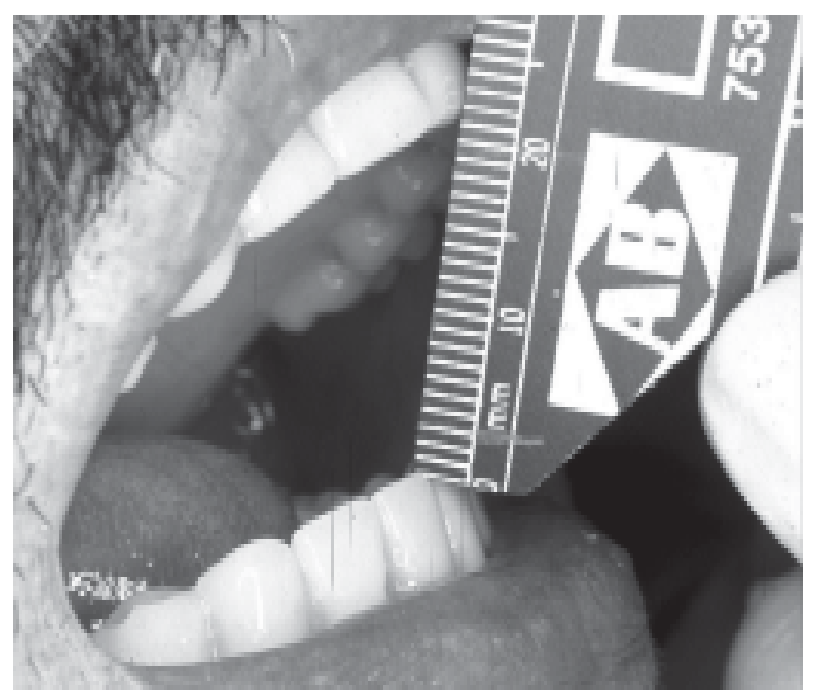

Figure 4. Measurement of mouth opening after oral rehabilitation. affected region.

Analysis of the images, obtained in both open and closed mouth positions, enabled a comparison of the relationship between the coronoid processes and the zygomatic processes, quantifying the distance between them, demonstrating that the proximity between the processes on the patient's right side acted as a mechanical impediment to free mandibular movement.

After formulation of the diagnosis, the situation was explained to the patient thereby creating an element of participation, mainly due to the fact that the appropriate therapeutic procedure for such hypertrophy of the condylar process would be, basically, reparative surgery. Faced with the above, the treatment option chosen by the patient, in common agreement with the professionals, was the re-establishment of the condition of oral health, though without surgical intervention on the coronoid process, in consideration of the systemic problems and patient's age.

Restriction of the mandibular movements is a symptom found in several diseases, thus making the formulation of a precise diagnosis difficult. The use of complementary exams for clarifying a clinical condition in doubt should be considered important.

Even when the diagnosis is conclusive, it is not always viable to make a recognized therapeutic procedure and a more conservative approach is required, provided that this is duly explained to the patient.

\section{RESUMO}

Este trabalho é o relato do caso clínico de um paciente que apresentava limitação de abertura bucal, porém, sem sintomatologia aparente, parcialmente desdentado e com exodontia indicada para os dentes remanescentes. Foram realizados exame clínico, anamnese e solicitação de radiografias panorâmica, transcraniana das articulações temporomandibulares e, posteriormente, tomografia computadorizada, ressaltando a importância de exames complementares na fase de diagnóstico. Pela análise da tomografia computadorizada, confirmou-se a alteração estrutural nos processos condilares e coronóide da mandíbula, justificando a abertura bucal reduzida. Os dentes remanescentes foram extraídos e próteses totais superior e inferior foram confeccionadas, restabelecendo o relacionamento oclusal e as funções estomatognáticas do paciente, não optando por tratamento cirúrgico do processo coronóide.

\section{REFERENCES}

1. Rieder CE. Maximal mandibular opening in patients with and without a history of TMJ dysfunction. J Prosthet Dent 1978;39:441-446. 
2. Agerberg G. Maximal mandibular movements in young men and women. Swed Dent J 1974;67:81-100.

3. Lundeen TF, Levitt SR, McKinney MW. Evaluation of temporomandibular joint disorders by clinician ratings. J Prosthet Dent 1988;59:202-211.

4. Sidelsky H, Clayton JA. A clinical study of joint sounds in subjects with restored occlusions. J Prosthet Dent 1990;63:580-586.

5. Mavili E, Akyurek M, Kayikcioglu A. Endoscopically assisted removal of unilateral coronoid process hyperplasia. Ann Plas Surg 1999;42:211-216.

6. Tieghi R, Galie M, Piersanti L, Clauser L. Bilateral hyperplasia of the coronoid processes. Clinical Report J Craniof Surg 2005;16:723-726.

7. Nickerson JW, Grafft ML, Sazima HJ. Bilateral coronoid process enlargement: report of case. J Oral Surg 1969;27:885890.

8. Kursoglu P, Capa N. Elongated mandibular coronoid process as a cause of mandibular hypomobility. J Craniomand Pract 2006;24:213-216.

9. Munk PL, Helms CA. Coronoid process hyperplasia: CT studies. Radiology 1989;171:783-784.

10. Honig JF, Merten HA, Korth OE, Halling F. Coronoid process enlargement. Dentomaxillofac Radiol 1994;23:108-110.

11. Totsuka Y, Fukuda H, Iizuka T, Shindoh M, Amemiya A. Osteochondroma of the coronoid process of the mandible. Report of a case showing histological evidence of neoplasia. J Craniomaxillofac Surg 1990;18:27-32.

Accepted April 26, 2004 